\title{
Empathizing with sensory and movement differences: moving toward sensitive understanding of autism
}

\author{
Steven K. Kapp* \\ *Correspondence: kapp@ucla.edu \\ Edited by: \\ Anne M. Donnellan, University of San Diego, USA \\ Reviewed by: \\ Anne M. Donnellan, University of San Diego, USA \\ Trevor McDonald, Education Associates Inc., USA
}

Human Development and Psychology Division, Graduate School of Education and Information Studies, University of California Los Angeles, Los Angeles, CA, USA

The autism diagnosis requires deficits in social interaction and communication, yet neither occurs in isolation. This brief literature-based analysis provides evidence that other factors are involved in autistic people's atypical social communication. The brain is a complicated system where regions serve multiple, general, and overlapping roles. Sensorimotor and broad cognitive processes underlie both neurotypicals' and autistics' social cognition and behavior. Sensory strengths sometimes underlie autistic people's difficulties, especially in dynamic contexts that require multimodal integration. Social abilities and behaviors occur between people in social contexts, and autistic and neurotypical people share mutual difficulties in understanding one another. This paper challenges attempts to reduce autism to social deficits, and suggests the need for better interpersonal and societal understanding of and support for autistic people.

\section{INTEGRATIVE NEUROSCIENCE}

Increasing evidence supports how brain networks integrate complex information, including the contribution of sensorimotor areas to abilities and behaviors considered social in autistic and neurotypical people. A recent study that sought to identify the components of autistic people's "social brain" identified a sensorimotor circuit as one of the subsystems (Gotts et al., 2012). Typically, as people learn and make sense of things, different parts of the brain are well-connected and function in sync and rhythm with one another, with activity oscillating back and forth (Wang, 2010; Uhlhass and Singer, 2012). Such wiring contributes to the rhythm and synchrony of typical social interaction, but these processes happen atypically in autistic people (for example, greater or less connectivity in certain areas compared with neurotypicals; Mostofsky and Ewen, 2011; Gomot and Wicker, 2012; Uddin et al., in press). Similarly, the cerebellum (Fatemi et al., 2012), basal ganglia (Qiu et al., 2010; Prat and Stocco, 2012), and sensorimotor cortex (Hamilton, 2013) brain structures known to assist motor control also connect to other regions and appear to play important roles in timing, speech production (Bouchard et al., 2013), the back-and-forth conversation (Scott et al., 2009) that is often problematic for autistic people.

A brain region called the insula exemplifies the complexity of challenges facing autistic people. Once considered to play a limited and isolated role (its name means "island"; Craig, 2010), the insula connects to diverse brain regions (Kurth et al., 2010; Deen et al., 2011). It is a key part of a brain network that integrates external sensory stimuli with one's own bodily, emotional, and mental states (Uddin and Menon, 2009), and which may best distinguish autism (Uddin et al., in press). Regarding the insula's role in subserving interoception (awareness of internal bodily stimuli; Craig, 2009), many autistic people are hypersensitive to pain (Nader et al., 2004) and can even have a highly accurate sense of their own heartbeat (Cascio et al., 2013). Interoception and the insula also contribute to a variety of social functions (Di Martino et al., 2009; Herbert and Pollatos, 2012), such as sharing attention with others (Mundy et al., 2010), and awareness of (Silani et al., 2008; Bird et al., 2010; Herbert et al., 2011) and verbal expression (Saxbe et al., 2012) of one's own emotions. Most autistic people have difficulties with interpreting and expressing their own emotions, but those more able to do so are less likely to have challenges with recognizing others' emotions (Bird et al., 2010), interpreting their facial expressions (Cook et al., 2013), or with making eye contact (Bird et al., 2011).

The insula also plays a role in unpleasant situations (Wicker et al., 2003; Wright et al., 2004; Jabbi et al., 2008). It contributes to autistic people's tendency for hypersensitivity to unpleasant textures, which-alongside hyposensitivity to other textures (Foss-Feig et al., 2012)—relates mostly to social impairment (Cascio et al., 2012b). Moreover, the insula is involved in the processing of norm violations (Sanfey et al., 2003), and autistic people show enhanced activation of the insula when rules are broken, which can create a false appearance (including in the insula) of reduced concern about social exclusion (Bolling et al., 2011; Masten et al., 2011). Indeed, the insula is involved in cognitive flexibility, including attention switching (Menon and Uddin, 2010) and tolerance for uncertainty, as well as understanding others' emotions (Singer et al., 2009). These are related, because people cannot mind-read, but rather approximate others' emotions and thoughts through probabilistic inference based on experience (Gopnik, 2011; Gopnik and Wellman, 2012).

\section{MIND-BODY INTERACTION}

Rather than relying on discrete social domains, interpreting other people's thoughts and emotions from their behavior or communication requires more general processes (Gernsbacher and Frymiare, 2005; Wilkinson and Ball, 2012). Typically, reading nonverbal 
cues involves sensorimotor and basic attentional processes, and happens relativelyautomatically and unconsciously (Pineda and Hecht, 2009; Frith and Frith, 2012). Autistic people tend to have significant challenges with all these abilities (Ben-Sasson et al., 2009; Kapp et al., 2011; Donnellan et al., 2013). Such challenges with reading body language relate to general trouble with movement; slowing down nonverbal cues significantly improves accuracy of processing them (Gepner and Féron, 2009). Autistics often demonstrate competence when processing the same stimulus when static but difficulties when in motion (Hanley et al., 2012; Weisberg et al., 2012). For example, many autistic people have oculomotor control (eye movement) problems, which challenge joint attention and language development (Mundy et al., 2009; Gliga et al., 2012; Kelly et al., 2013). In particular, many autistic people's pupils reflect intense activity in the nervous system, which challenges quick, coordinated, spontaneous attention (Anderson et al., 2012). Faced with these difficulties, most autistic people learn to rely on more advanced active reasoning skills to infer body language (Ahmed and Miller, 2011; Vivanti et al., 2011; Senju, 2013).

Like sensory processing (Aglioti and Pazzaglia, 2011) and movement (Riley et al., 2012) in neurotypicals, sensorimotor differences in autistic people underlie various behaviors impacting social functioning. For example, sensory hypersensitivity and integration difficulties often lead to social withdrawal from overload (Reynolds et al., 2011; Brock et al., 2012), while the slow responsiveness from sensory hyposensitivity distinctively contributes to autism-related impairment (Ben-Sasson et al., 2009; Brock et al., 2012). Furthermore, challenges with body posture and gestures, listed as impairment in social interaction in the autism diagnosis (APA, 2000), relate to respective difficulties with postural control (from poor balance; Travers et al., 2012) and performing skilled movements (related to dyspraxia: impairment in motor planning; Dziuk et al., 2007). Similarly, atypical social distance (personal space; Frazier et al., 2012) may stem from problems sensing and orienting to one's body in space (Blanche et al., 2012).
Moreover, as in the general population (Niedenthal, 2007; Barsalou, 2008), emotions and language in autistic people are grounded in the body. When autistics have challenges with social emotions, these draw from embodied emotion dysregulation more broadly (Winkielman et al., 2009; Mazefsky et al., 2012). Likewise, when autistics have challenges understanding figurative language and other aspects of what often gets labeled as pragmatics (language applied to social contexts), this stems from general challenges with receptive (understanding) language (Gernsbacher and Pripas-Kapit, 2012). While language is acquired through social contexts, speech requires the coordination of many muscles; most autistics have atypical speech (whether functional or not), including unusual prosody (rate, rhythm, volume, pitch, and tone; Eigsti et al., 2011).

Although proponents of social deficit theories of autism often emphasize poor autobiographical memory, this originates in part from the sense of smell and broader memory problems. Certain odors automatically induce memories and social contact in neurotypicals (Larsson and Willander, 2009), but the effect may tend to be limited to more familiar events and people in autistics (Parma et al., 2013). Indeed, a few studies have linked tastesmell processing difficulties in autistics with greater communication and behavioral challenges (Hilton et al., 2010; Lane et al., 2011). Moreover, autistics tend to have challenges with not only past- but also future-oriented memory (prospective memory: remembering to carry out intentions); this contributes to planning, organization, multitasking, and social cognitive challenges (Rajendran et al., 2011; Lind and Williams, 2012; Williams et al., 2012).

\section{COMPLEX DIFFERENCES}

Any comprehensive theory of autism requires recognizing the complex nature of differences, including strengths and impairments that sometimes arise from them, as illustrated in the visual and auditory modalities. Visual strengths relate positively to language and other communication challenges (Atkinson, 2009; Joseph et al., 2009; Hubbard et al., 2012; Ohta et al., 2012); most autistics considered "untestable" can demonstrate visu- ospatial skills (Courchesne et al., 2012). Autistics tend to have enhanced ability, and natural orientation, to directly process visual stimuli (Happé and Frith, 2006; Mottron et al., 2006; Simmons et al., 2009), including the abilities to search for objects amid distractors, see patterns, and notice subtle changes in scenery (Simmons et al., 2009). Yet, for some, this hypersensitivity means pain (Kleinhans et al., 2010) or distraction (Doherty-Sneddon et al., 2012) from eye contract or bright lights (Fan et al., 2009), and aversion to change related to heightened recognition of subtle changes in the environment (Cléry et al., 2013a,b).

Similarly, autistic people's auditory strengths relate positively to their language challenges (Bonnel et al., 2010). Autistics tend to have greater perception of singular auditory stimuli such as absolute ("perfect") pitch (Happé and Frith, 2006; Mottron et al., 2006; O'Connor, 2012), but hypersensitivity can mean greater pain from loud noise (Egelhoff and Lane, 2013), impairment in filtering out background noise (Lane et al., 2010; Egelhoff and Lane, 2013), and difficulty learning spoken words (Norbury et al., 2010). Because of general challenges with audiovisual integration when watching and listening to speech (Woynaroski et al., 2013), autistics tend to look at the mouth, which provides audiovisual synchrony (lip motion with speech sound; Klin et al., 2009) that helps autistics and typically developing infants develop language skills (Norbury et al., 2009; Young et al., 2009; Falck-Ytter et al., 2010; Lewkowicz and Hansen-Tift, 2012).

Indeed, the greatest differences often stem from simultaneous multisensory processing and integration of information more broadly. For example, related to visual-motor integration challenges, many autistics learn new movements (Haswell et al., 2009; Izawa et al., 2012) and facial expressions (Wright et al., 2008) by focusing on feedback from the body more than visual observation; autistics with especially low body awareness may struggle greatly with motor skills and communication (Freitag et al., 2007; Blanche et al., 2012; Linkenauger et al., 2012). Neurotypicals unconsciously integrate information, and their prior experiences and expectations shape their perception of surroundings (Schroeder et al., 2010; Meyer, 2011). 
Autistics are also affected by this phenomenon, but more independent processing grounded in details of the environment can translate to more realistic perception (Brock, 2012; Cascio et al., 2012a; Pellicano and Burr, 2012). Yet for many this also means overwhelm and confusion in everyday settings that require dynamic online (in the moment) integration (Dinstein et al., 2012), and lack of automatic attention (but generally not inability to understand) the "big picture" or context, which contributes to communication challenges (Happé and Frith, 2006).

\section{PERSON-ENVIRONMENT (SOCIAL) INTERACTION}

Despite their inclusion in the autism diagnosis as an internal problem, communication, reciprocity, and relationships happen between people and must happen both ways to function (Donnellan et al., 2013). According to the concept of synchrony, effective communication happens not only between regions of a person's brain, but between communication partners, whose brains and bodies in turn will typically reflect mutual engagement (Hari et al., 2013). While people typically show neural synchrony when engaged in joint activity, autistic people and neurotypical communication partners both have challenges connecting with one another, demonstrated neurologically and behaviorally (Tanabe et al., 2012; Schilbach et al., in press). In spite of the listing of impairment in peer relationships within the autism diagnosis (APA, 2000), peers regularly bully and reject autistics, and are generally more likely to do so if the autistic person gets upset (Rieffe et al., 2012) or withdraws (Humphrey and Symes, 2010). Such stressful experiences cause and exacerbate co-occurring mental and physical conditions (Kohane et al., 2012), and present greater challenges for coping with autism.

Supporting autistic people requires flexibility between autistics and communication partners (Muskett et al., 2010). For example, autistic children tend to build more skills when their parents understand and accept them (Kapp et al., 2013; Oppenheim and Koren-Karie, unpublished). Such sensitivity requires learning why someone has particular behavior and working with the person (Amos, 2013); even challenging behavior may represent an adaptive form of compensatory communication (Damico and Nelson, 2005). Parents who understand the reasons for their autistic children's behaviors and learn to speak their child's language help their child gain skills in the parent's language, especially for more language delayed or impaired children, by becoming in sync with their child (Kasari et al., 2008; Perryman et al., 2012; Haebig et al., 2013; Siller et al., 2013).

Now that the autism field has begun to intensively study sensory-movement differences, they have become better understood, with potential to spur change. Autistics' challenges with sensory processing, motor skills, emotion regulation, and executive functioning often mask the extent or expression of their social understanding or interest in neurotypical contexts. Neurotypicals do not naturally recognize the full reasons for sensorymovement differences, and their centrality to communication differences, because they involve areas they process intuitively. Critically, as scientific evidence on the presence and importance of autistic people's sensory-movement differences mounts, it increasingly reflects autistic people's lived experiences (Chamak et al., 2008; Davidson and Henderson, 2010; Robledo et al., 2012). What society does with this knowledge will test everyone's sensitivity and understanding.

\section{ACKNOWLEDGMENTS}

I am grateful to K. C. Berry, Shannon Des Roches Rosa, Emmy Goldknopf (who also helped with the submission process), Hilary Gould, Lianna Hartmour, Jill Jones, Christina Nicolaidis, Sarah Elizabeth Pelangka, Sarah Pripas-Kapit, Jeffrey Rudie, Kassiane Alexandra Sibley, Amanda Vivian, and the reviewer for their feedback. Much thanks also to Frontiers and special issue editors Liz Torres and Anne Donnellan, whose theory with Martha Leary and David Hill inspired this paper.

\section{REFERENCES}

Aglioti, S. M., and Pazzaglia, M. (2011). Sounds and scents in (social) action. Trends Cogn. Sci. 15, 47-55.

Ahmed, F. S., and Miller, L. S. (2011). Executive function mechanisms of theory of mind. J. Autism Dev. Disord. 41, 667-678.
American Psychiatric Association. (2000). Diagnostic and Statistical Manual of Mental disorders: Text Revision. 4th Edn. Washington, DC: Author.

Amos, P. (2013). Rhythm and timing in autism: learning to dance. Front. Intgr. Neurosci. 7:27. doi: 10.3389/fnint.2013.00027.

Anderson, C. J., Colombo, J., and Unruh, K. E. (2012). Pupil and salivary indicators of autonomic dysfunction in autism spectrum disorder. Dev. Psychobiol. doi: 10.1002/dev.21051. [Epub ahead of print].

Atkinson, A. P. (2009). Impaired recognition of emotions from body movements is associated with elevated motion coherence thresholds in autism spectrum disorders. Neuropsychologia 47, 3023-3029.

Barsalou, L. W. (2008). Grounded cognition. Annu. Rev. Psychol. 59, 617-645.

Ben-Sasson, A., Len, L., Fluss, R., Cermak, S. A., Engel-Yeger, B., and Gal, E. (2009). A metaanalysis of sensory modulation symptoms in individuals with autism spectrum disorders. J. Autism Dev. Disord. 39, 1-11.

Bird, G., Press, C., and Richardson, D. C. (2011). The role of alexithymia in reduced eye-fixation in autism spectrum conditions. J. Autism Dev. Disord. 41, 1556-1564.

Bird, G., Silani, G., Brindley, R., White, S., Frith, U., and Singer, T. (2010). Empathic brain responses in insula are modulated by levels of alexithymia but not autism. Brain 133, 1515-1525.

Blanche, E. I., Reinoso, G., Chang, M. C., and Bodison, S. (2012). Proprioceptive processing difficulties among children with autism spectrum disorders and developmental disabilities. Am. J. Occup. Ther. 66, 621-624.

Bolling, D. Z., Pitskel, N. B., Deen, B., Crowley, M. J., McPartland, J. C., Kaiser, M. D., et al. (2011). Enhanced neural responses to rule violation in children with autism: a comparison to social exclusion. Dev. Cogn. Neurosci. 1, 280-294.

Bonnel, A., McAdams, S., Smith, B., Berthiaume, C., Bertone, A., Ciocca, V., et al. (2010). Enhanced pure-tone pitch discrimination among persons with autism but not Asperger syndrome. Neuropsychologia 48, 2465-2475.

Bouchard, K. E., Mesgarani, N., Johnson, K., and Chang, E. F. (2013). Functional organization of human sensorimotor cortex for speech articulation. Nature 495, 327-332.

Brock, J. (2012). Alternative Bayesian accounts of autistic perception: comment on Pellicano and Burr. Trends Cogn. Sci. 16, 573-574.

Brock, M. E., Freuler, A., Baranek, G. T., Watson, L. R., Poe, M. D., and Sabatino, A. (2012). Temperament and sensory features of children with autism. J. Autism Dev. Disord. 42, 2271-2284.

Cascio, C., Loring, W. A., and Schauder, K. (2013). "Superior interoception in children with autism spectrum disorders," in Presentation at International Meeting for Autism Research, (San Sebastián).

Cascio, C. J., Foss-Feig, J. H., Burnette, C. P., Heacock, J. L., and Cosby, A. A. (2012a). The rubber hand illusion in children with autism spectrum disorders: delayed influence of combined tactile and visual input on proprioception. Autism 16, 406-419.

Cascio, C. J., Moana-Filho, E. J., Guest, S., Nebel, M. B., Weisner, J., Baranek, G. T., et al. (2012b). 
Perceptual and neural response to affective tactile texture stimulation in adults with autism spectrum disorders. Autism Res. 5, 231-244.

Chamak, B., Bonniau, B., Jaunay, E., and Cohen, D. (2008). What can we learn about autism from autistic persons? Psychother. Psychosom. 77, 271-279.

Cléry, H., Bonnet-Brilhault, F., Lenoir, P., Barthelemy, C., Bruneau, N., and Gomot, M. (2013a). Atypical visual change processing in children with autism: an electrophysiological study. Psychophysiology. 50, 240-252.

Cléry, H., Roux, S., Houy-Durand, E., BonnetBrilhault, F., Bruneau, N., and Gomot, M. (2013b). Electrophysiological evidence of atypical visual change detection in adults with autism. Front. Hum. Neurosci. 7:62. doi: 10.3389/fnhum.2013.00062

Cook, R., Brewer, R., Shah, P., and Bird, G. (2013). Alexithymia, not autism, predicts poor recognition of emotional facial expressions. Psyochol. Sci. doi: 10.1177/0956797612463582. [Epub ahead of print].

Courchesne, V., Simard-Neilleur, A. A., and Soulières, I. (2012). "Intelligence testing in autistic children regarded as very "low-functioning": the good surprise," in Paper presented at International Meeting for Autism Research (Toronto, OR).

Craig, A. D. (2009). How do you feel - now? The anterior insula and human awareness. Nat. Rev. Neurosci. 10, 59-70.

Craig, A. D. (2010). Once an island, now the focus of attention. Brain Struct. Funct. 214, 395-396.

Damico, J. S., and Nelson, R. L. (2005). Interpreting problematic behavior: systematic compensatory adaptations as emergent phenomena in autism. Clin. Linguist. Phonet. 19, 405-417.

Davidson, J., and Henderson, V. L. (2010). 'Travel in parallel with us for a while': sensory geographies of autism. Can. Geogr. 54, 462-475.

Deen, B., Pitskel, N. B., and Pelphrey, K. A. (2011). Three systems of insular functional connectivity identified with cluster analysis. Cereb. Cortex 21, 1498-1506.

Di Martino, A., Ross, K., Uddin, L. Q., Sklar, A. B., Castellanos, F. X., and Milham, M. P. (2009). Functional brain correlates of social and nonsocial processes in autism spectrum disorders: an activation likelihood estimation meta-analysis. Biol. Psychol. 65, 63-74.

Dinstein, I., Heeger, D. J., Lorenzi, L., Minshew, N. J., Malach, R., and Behrmann, M. (2012). Unreliable evoked responses in autism. Neuron 75 , 981-991.

Doherty-Sneddon, G., Riby, D. M., and Whittle, L. (2012). Gaze aversion as a cognitive load management strategy in autism spectrum disorder and Williams syndrome. J. Child Psychol. Psyc. 53, 420-430.

Donnellan, A. M., Hill, D. A., and Leary, M. R. (2013). Rethinking autism: implications of sensory and movement differences for understanding and support. Front. Integr. Neurosci. 6:124. doi: 10.3389/fnint.2012.00124

Dziuk, M. A., Gidley Larson, J. C., Apostu, A., Mahone, E. M., Denckla, M. B., and Mostofsky, S. H. (2007). Dyspraxia in autism: association with motor, social, and communicative deficits. Dev. Med. Child Neurol. 49, 734-739.
Egelhoff, K., and Lane, A. E. (2013). Brief report: preliminary reliability, construct validity and standardization of the auditory behavior questionnaire (ABQ) for children with autism spectrum disorders. J. Autism Dev. Disord. 43, 978-984.

Eigsti, I. E., de Marchena, A. B., Schuh, J. M., and Kelley, E. (2011). Language acquisition in autism spectrum disorders: a developmental review. Res. Autism Spect. Dis. 5, 681-691.

Falck-Ytter, T., Fernell, E., Gillberg, C., and Von Hofsten, C. (2010). Face scanning distinguishes social from communication impairments in autism. Dev. Sci. 13, 864-875.

Fan, X., Miles, J. H., Takahashi, N., and Yao, G. (2009). Abnormal transient papillary light reflex in individuals with autism spectrum disorders. J. Autism Dev. Disord. 39, 1499-1508.

Fatemi, S. H., Aldinger, K. A., Ashwood, P., Bauman, M. L., Blaha, C. D., Blatt, G. J., et al. (2012). Consensus paper: pathological role of the cerebellum in autism. Cerebellum 11, 777-807.

Foss-Feig, J. H., Heacock, J. L., and Cascio, C. J. (2012). Tactile responsiveness patterns and their association with core features in autism spectrum disorders. Res. Autism Spect. Dis. 6, 337-344.

Frazier, T. W., Youngstrom, E. A., Speer, L., Embacher, R., Law, P., Constantino, J., et al. (2012). Validation of proposed DSM-5 criteria for autism spectrum disorder. J. Am. Acad. Child Adolesc. Psychiatry 51, $28-40$.

Freitag, C. M., Kleser, C., Schneider, M., and von Gontard, A. (2007). Quantitative assessment of neuromotor function in adolescents with high functioning autism and Asperger syndrome. J. Autism Dev. Disord. 37, 948-959.

Frith, C. D., and Frith, U. (2012). Mechanisms of social cognition. Annu. Rev. Psychol. 63, 287-313.

Gepner, B., and Féron, F. (2009). Autism: a world changing too fast for a mis-wired brain? Neurosci. Biobehav. Rev. 33, 1227-1242.

Gernsbacher, M. A., and Frymiare, J. L. (2005). Does the autistic brain lack core modules? J. Dev. Learn. Disord. 9, 3-16.

Gernsbacher, M. A., and Pripas-Kapit, S. R. (2012). Who's missing the point? A commentary on claims that autistic persons have a specific deficit in figurative language comprehension. Metaphor Symb. 27, 93-105.

Gliga, T., Elsabbagh, M., Hudry, K., Charman, T., and Johnson, M. H. (2012). Gaze following, gaze reading, and word learning in children at risk for autism. Child Dev. 83, 926-938.

Gomot, M., and Wicker, B. (2012). A challenging, unpredictable world for people with autism spectrum disorder. Int. J. Psychophysiol. 83, 240-247.

Gopnik, A. (2011). The theory theory 2.0: probabilistic models and cognitive development. Child Dev. Perspect. 5, 161-163.

Gopnik, A., and Wellman, H. M. (2012). Reconstructing constructivism: casual models, Bayesian learning mechanisms, and the theory theory. Psychol. Bull. 138, 1085-1108.

Gotts, S. J., Simmons, W. K., Milbury, L. A., Wallace, G. L., Cox, R. W., and Martin, A. (2012). Fractionation of social brain circuits in autism spectrum disorders. Brain 135, 2711-2725.

Haebig, E., McDuffie, A., and Weismer, S. E (2013). Brief report: parent verbal responsiveness and language development in toddlers on the autism spectrum. J. Autism Dev. Disord. doi: 10.1007/s10803-013-1763-5. [Epub ahead of print].

Hamilton, A. (2013). Reflecting on the mirror neuron system in autism: a systematic review of current theories. Dev. Cogn. Neurosci. 3, 91-105.

Hanley, M., McPhillips, M., Mulhern, G., and Riby, D. M. (2012). Spontaneous attention to faces in Asperger Syndrome using ecologically valid static stimuli. Autism doi: 10.1177/1362361312456746. [Epub ahead of print].

Happé, F., and Frith, U. (2006). The weak coherence account: detail-focused cognitive style in autism spectrum disorders. J. Autism Dev. Disord. 36, $5-25$.

Hari, R., Himberg, T., Nummenmaa, L., Hämäläinen, M., and Parkkonen, L. (2013). Synchrony of brains and bodies during implicit interpersonal interaction. Trends Cogn. Sci. 17, 105-106.

Haswell, C. C., Izawa, J., Dowell, R., Mostofsky, S., and Shadmehr, R. (2009). Representation of internal models of action in the autistic brain. Nat. Neurosci. 12, 970-972.

Herbert, B. M., Herbert, C., and Pollatos, O. (2011). On the relationship between interoceptive awareness and alexithymia: is interoceptive awareness related to emotional awareness? J. Pers. 79, 1149-1175.

Herbert, B. M., and Pollatos, O. (2012). The body in the mind: on the relationship between interoception and embodiment. Top. Cogn. Sci. 4, 692-704.

Hilton, C. L., Harper, J. D., Kueker, R. H., Lang, A. R., Abbacchi, A. A., Todorov, A., et al. (2010). Sensory responsiveness as a predictor of social severity in children with high functioning autism spectrum disorders. J. Autism Dev. Disord. 40, 937-945.

Hubbard, A. L., McNealy, K., Scott-Van Zeeland, A. A., Callan, D. E., Bookheimer, S. Y., and Dapretto, M. (2012). Altered integration of speech and gesture in children with autism spectrum disorders. Brain Behav. 2, 606-619.

Humphrey, N., and Symes, W. (2010). Responses to bullying and use of social support among pupils with autism spectrum disorders (ASDs) in mainstream schools: a qualitative study. J. Res. Spec. Educ. Needs 10, 82-90.

Izawa, J., Pekny, S. E., Marko, M. K., Haswell, C. C., Shadmehr, R., and Mostofsky, S. H. (2012). Motor learning relies on integrated sensory inputs in ADHD, but over-selectively on proprioception in autism spectrum conditions. Autism Res. 5, 124-136.

Jabbi, M., Bastiaansen, J., and Keysers, C. (2008). A common anterior insula representation of disgust observation, experience and imagination shows divergent functional connectivity pathways. PLoS ONE 3:e2939. doi: 10.1371/journal.pone.0002939

Joseph, R. M., Keehn, B., Connolly, C., Wolfe, J. M., and Horowitz, T. S. (2009). Why is visual search superior in autism spectrum disorder? Dev. Sci. 12, 1083-1096.

Kapp, S. K., Gantman, A., and Laugeson, E. A. (2011). "Transition to adulthood for high-functioning individuals with autism spectrum disorders," in A Comprehensive Book on Autism Spectrum Disorders, ed M.-R. Mohammadi (Rijeka: InTech), 451-478.

Kapp, S. K., Gillespie-Lynch, K., Sherman, L. E., and Hutman, T. (2013). Deficit, difference, or 
both? Autism and neurodiversity. Dev. Psychol. 49, 59-71.

Kasari, C., Paparella, T., Freeman, S., and Jahromi, L. B. (2008). Language outcome in autism: randomized comparison of joint attention and play interventions. J. Consult. Clin. Psychol. 76, 125-137.

Kelly, D. J., Walker, R., and Norbury, C. F. (2013). Deficits in volitional oculomotor control align with language status in autism spectrum disorders. Dev. Sci. 16, 56-66.

Kleinhans, N. M., Richards, T., Weaver, K., Johnson, L. C., Greenson, J., Dawson, G., et al. (2010). Association between amygdala response to emotional faces and social anxiety in autism spectrum disorders. Neuropsychologia 48, 3665-3670.

Klin, A., Lin, D. J., Gorrindo, P., Ramsey, G., and Jones, W. (2009). Two-year-olds with autism orient to nonsocial contingencies rather than biological motion. Nature 459, 257-261.

Kohane, I. S., McMurry, A., Weber, G., MacFadden, D., Rappaport, L., Kunkel, L., et al. (2012). The comorbidity burden of children and young adults with autism spectrum disorders. PLOS ONE 7:e33224. doi: 10.1371/journal.pone.0033224

Kurth, F., Zilles, K., Fox, P. T., Laird, A. R., and Eickhoff, S. B. (2010). A link between the systems: Functional differentiation and integration within the human insula revealed by meta-analysis. Brain Struct. Funct. 214, 519-534.

Lane, A. E., Dennis, S. J., and Geraghty, M. E. (2011). Brief report: further evidence of sensory subtypes in autism. J. Autism Dev. Disord. 41, 826-831.

Lane, A. E., Young, R. L., Baker, A. E., and Angley, M. T. (2010). Sensory processing subtypes in autism: association with adaptive behavior. J. Autism Dev. Disord. 40, 112-122.

Larsson, M., and Willander, J. (2009). Autobiographical odor memory. Ann. N.Y. Acad. Sci. 1170, 318-323.

Lewkowicz, D. J., and Hansen-Tift, A. M. (2012). Infants deploy selective attention to the mouth of a talking face when learning speech. Proc. Natl. Acad. Sci. U.S.A. 109, 1431-1436.

Lind, S. E., and Williams, D. M. (2012). The association between past and future thinking: evidence from autism spectrum disorder. Learn. Motiv. 43, 231-240.

Linkenauger, S. A., Lerner, M. D., Ramenzoni, V. C., and Proffitt, D. R. (2012). A perceptual-motor deficit predicts social and communicative impairments in individuals with autism spectrum disorder. Autism Res. 5, 352-362.

Masten, C. L., Colich, N. L., Rudie, J. D., Bookheimer, S. Y., Eisenberger, N. I., and Dapretto, M. (2011). An fMRI investigation of responses to peer rejection in adolescents with autism spectrum disorders. Dev. Cogn. Neurosci. 1, 260-270.

Mazefsky, C. A., Pelphrey, K. A., and Dahl, R. E. (2012). The need for a broader approach to emotion regulation research in autism. Child Dev. Perspect. 6, 92-97.

Menon, V., and Uddin, L. Q. (2010). Saliency, switching, attention and control: a network model of insula function. Brain Struct. Func. 214, 655-667.

Meyer, K. (2011). Primary sensory cortices, topdown projections and conscious experience. Prog. Neurobiol. 94, 408-417.
Mostofsky, S. H., and Ewen, J. B. (2011). Altered connectivity and action model formation in autism is autism. Neuroscientist 17, 437-448.

Mottron, L., Dawson, M., Soulières, I., Hubert, B., and Burack, J. (2006). Enhanced perceptual functioning in autism: an update, and eight principles of autistic perception. J. Autism Dev. Disord. 36, $27-43$.

Mundy, P., Gwaltney, M., and Henderson, H. (2010). Self-referenced processing, neurodevelopment and joint attention in autism. Autism 14, 408-429.

Mundy, P., Sullivan, L., and Mastergeorge, A. M. (2009). A parallel and distributed-processing model of joint attention, social cognition, and autism. Autism Res. 2, 2-21.

Muskett, T., Perkins, M., Clegg, J., and Body, R. (2010). Inflexibility as an interactional phenomenon: using conversation analysis to reexamine a symptom of autism. Clin. Linguist. Phonet. 24, 1-16.

Nader, R., Oberlander, T. F., Chambers, C. T., and Craig, K. D. (2004). Expression of pain in children with autism. Clin. J. Pain 20, 88-97.

Niedenthal, P. M. (2007). Embodying emotion. Science 316, 1002-1005.

Norbury, C. F., Brock, J., Cragg, L., Einav, S., Griffiths, H., and Nation, K. (2009). Eye-movement patterns are associated with communicative competence in autistic spectrum disorders. J. Child Pschol. Psychiatry 50, 834-842.

Norbury, C. F., Griffiths, H., and Nation, K. (2010). Sound before meaning: word learning in autistic disorders. Neuropsychologia 48, 4012-4019.

O'Connor, K. (2012). Auditory processing in autism spectrum disorder: a review. Neurosci. Biobehav. Rev. 36, 836-854.

Ohta, H., Yamada, T., Watanabe, H., Kanai, C., Tanaka, E., Ohno, T., et al. (2012). An fMRI study of reduced perceptual load-dependent modulation of task-irrelevant activity in adults with autism spectrum conditions. Neuroimage 61, 1176-1187.

Parma, V., Bulgheroni, M., and Tirindelli, R. (2013). Body odors promote automatic imitation in autism. Biol. Psychiatry. doi: 10.1016/j.biopsych.2013.01.010. [Epub ahead of print].

Pellicano, E., and Burr, D. (2012). When the world becomes 'too real': a Bayesian explanation of autistic perception. Trends Cogn. Sci. 16, 504-510.

Perryman, T. Y., Carter, A. S., Messinger, D. S., Stone, W. L., Ivanescu, A. E., and Yoder, P. J. (2012). Brief report: parental child-directed speech as a predictor of receptive language in children with autism symptomatology. J. Autism Dev. Disord. doi: 10.1007/s10803-012-1725-3. [Epub ahead of print].

Pineda, J. A., and Hecht, E. (2009). Mirroring and mu rhythm involvement in social cognition: are there dissociable subcomponents of theory of mind? Biol. Psychol. 80, 306-314.

Prat, C. S., and Stocco, A. (2012). Information routing in the basal ganglia: highways ot abnormal connectivity in autism?: comment on "Disrupted cortical connectivity theory as an explanatory model for autism spectrum disorders by Kana et al. Phys. Life Rev. 9, 1-2.

Qiu, A., Adler, M., Crocetti, D., and Mostofsky, S. H. (2010). Basal ganglia shapes predict social, communication, and motor dysfunctions in boys with autism spectrum disorder. J. Am. Acad. Child Adolesc. Psychiatry 49, 539-551.

Rajendran, G., Law, A. S., Logie, R. H., van der Meulen, M., Fraser, D., and Corley, M. (2011). Investigating multitasking in high-functioning adolescents with autism spectrum disorders using the Virtual Errands Task. J. Autism Dev. Disord. 41, 1445-1454.

Reynolds, S., Bendixen, R. M., Lawrence, T., and Lane, S. J. (2011). A pilot study examining activity participation, sensory responsiveness, and competence in children with high functioning autism spectrum disorder. J. Autism Dev. Disord. 41, 1496-1506

Rieffe, C., Camodeca, M., Pouw, L. B. C., Lange, A. M. C., and Stockmann, L. (2012). Don't anger me! Bullying, victimization, and emotion dysregulation in young adolescents with ASD. Eur. J. Dev. Psychol. 9, 351-370.

Riley, M. A., Shockley, K., and Van Orden, G. (2012). Learning from the body about the mind. Topics Cogn. Sci. 4, 21-34.

Robledo, J., Donnellan, A., and Strandt-Conroy, K. (2012). An exploration of sensory and movement differences from the perspective of individuals with autism. Front. Integr. Neurosci. 6:107. doi: 10.3389/fnint.2012.00107

Sanfey, A. G., Rilling, J. K., Aronson, J. A., Nystrom, L. E., and Cohen, J. D. (2003). The neural basis of economic decision-making in the Ultimatum Game. Science 300, 1755-1758.

Saxbe, D. E., Yang, X. F., Borofsky, L. A., and Immordino-Yang, M. H. (2012). The embodiment of emotion: language use during the feeling of social emotions predicts cortical somatosensory activity. Soc. Cogn. Affect. Neurosci. doi: 10.1093/scan/nss075. [Epub ahead of print].

Schilbach, L., Timmermans, B., Reddy, V., Costall, A. Bente, G., Schlicht, T., et al. (in press). Toward a second-person neuroscience. Behav. Brain Sci.

Schroeder, C. E., Wilson, D. A., Radman, T., Scharfman, H., and Lakatos, P. (2010). Dynamics of active sensing and perceptual selection. Curr. Opin. Neurobiol. 20, 172-176.

Scott, S. K., McGettigan, C., and Eisner, F. (2009). A little more conversation, a little less action-candidate roles for the motor cortex in speech perception. Nat. Rev. Neurosci. 10, 295-302.

Senju, A. (2013). Atypical development of spontaneous social cognition in autism spectrum disorders. Brain Dev. 35, 95-101

Silani, G., Bird, G., Brindley, R., Singer, T., Frith, C., and Frith, U. (2008). Levels of emotional awareness and autism: an fMRI study. Soc. Neurosci. 3, 97-112.

Siller, M., Hutman, T., and Sigman, M. (2013). A parent-mediated intervention to increase responsive parental behaviors and child communication in children with ASD: a randomized clinical trial. J. Autism Dev. Disord. 43, 540-555.

Simmons, D. R., Robertson, A. E., McKay, L. S., Toal, E., McAleer, P., and Pollick, F. E. (2009). Vision in autism spectrum disorders. Vision Res. 49, 2705-2739.

Singer, T., Critchley, H. D., and Preuschoff, K. (2009). A common role of insula in feelings, empathy and uncertainty. Trends Cogn. Sci. 13, 334-340. 
Tanabe, H. C., Kosaka, H., Saito, D. N., Koike, T., Hayashi, M. J., Izuma, K., et al. (2012). Hard to "tune in": neural mechanisms of live face-to-face interaction with high-functioning autistic spectrum disorder. Front. Hum. Neurosci. 6:268. doi: 10.3389/fnhum.2012.00268

Travers, B. G., Powell, P. S., Klinger, L. G., and Klinger, M. R. (2012). Motor difficulties in autism spectrum disorder: linking symptom severity and postural stability. J. Autism Dev. Disord. doi: 10.1007/s10803-012-1702-x. [Epub ahead of print].

Uddin, L. Q., and Menon, V. (2009). The anterior insula in autism: under-connected and under-examined. Neurosci. Biobehav. Rev. 33, 1198-1203.

Uddin, L. Q., Superkar, K., Lynch, C., Khouzam, A., Phillips, J., Feinstein, C., et al. (in press). Salience network based classification and prediction of symptom severity in children with autism. JAMA Psychiatry.

Uhlhass, P. J., and Singer, W. (2012). Neuronal dynamics and neuropsychiatric disorders: toward a translational paradigm for dysfunctional large-scale networks. Neuron 75, 963-980.

Vivanti, G., McCormick, C., Young, G. S., Abucayan, F., Hatt, N., Nadig, A., et al. (2011). Intact and impaired mechanisms of action understanding in autism. Dev. Psychol. 47, 841-856.

Wang, X.-J. (2010). Neurophysiological and computational principles of cortical rhythms in cognition. Physiol. Rev. 90, 1195-1268.
Weisberg, J., Milleville, S. C., Kenworthy, L., Wallace, G. L., Gotts, S. J., Beauchamp, M. S., et al. (2012). Social perception in autism spectrum disorders: impaired category selectivity for dynamic but not static images in ventral temporal cortex. Cereb. Cortex. doi: 10.1093/cercor/bhs276. [Epub ahead of print].

Wicker, B., Keysers, C., Plailly, J., Royet, J. P., Gallese, V., and Rizzolatti, G. (2003). Both of us disgusted in my insula: the common neural basis of seeing and feeling disgust. Neuron 40, 655-664.

Wilkinson, M. R., and Ball, L. J. (2012). Why studies of autism spectrum disorders have failed to resolve the theory theory versus simulation theory debate. Rev. Philos. Psychol. 3, 263-291.

Williams, D., Boucher, J., Lind, S., and Jarrold, C. (2012). Time-based and event-based prospective memory in autism spectrum disorder: the roles of executive function and theory of mind, and time-estimation. J. Autism Dev. Disord. doi: 10.1007/s10803-012-1703-9. [Epub ahead of print].

Winkielman, P., McIntosh, D. N., and Oberman, L. (2009). Embodied and disembodied emotion processing: learning from and about typical and autistic individuals. Emot. Rev. 1, 178-190.

Woynaroski, T. G., Kwakye, L. D., Foss-Feig, J. H. Stevenson, R. A., Stone, W. L., and Wallace, M. T. (2013). Multisensory speech perception in children with autism spectrum disorders. J. Autism Dev. Disord. doi: 10.1007/s10803-0131836-5. [Epub ahead of print].
Wright, B., Clarke, N., Jordan, J. O., Young, A. W., Clarke, P., Miles, J., et al. (2008). Emotion recognition in faces and the use of visual context Vo in young people with highfunctioning autism spectrum disorders. Autism 12, 607-626.

Wright, P., He, G., Shapira, N. A., Goodman, W. K., and Liu, Y. (2004). Disgust and the insula: fMRI responses to pictures of mutilation and contamination. Neuroreport 15, 2347-2351.

Young, G. S., Merin, N., Rogers, S. J., and Ozonoff, S. (2009). Gaze behavior and affect at 6 months: predicting clinical outcomes and language development in typically developing infants and infants at risk for autism. Dev. Sci. 12, 798-814.

Received: 11 April 2013; accepted: 30 April 2013; published online: 24 May 2013.

Citation: Kapp SK (2013) Empathizing with sensory and movement differences: moving toward sensitive understanding of autism. Front. Integr. Neurosci. 7:38. doi: $10.3389 /$ fnint.2013.00038

Copyright (c) 2013 Kapp. This is an open-access article distributed under the terms of the Creative Commons Attribution License, which permits use, distribution and reproduction in other forums, provided the original authors and source are credited and subject to any copyright notices concerning any third-party graphics etc. 